\title{
DE PROFESSOR A TUTOR: DESEJO E DISCURSOS NA ARTICULAÇÃO ENTRE PBL E PSICANÁLISE
}

\section{FROM PROFESSOR TO TUTOR: DESIRE AND DISCOURSE BETWEEN PBL AND PSYCHOANALYSIS}

\section{Lêda Lessa Andrade Filha', Maria Luiza Sarno Castro}

Autora para correspondência: Lêda Lessa Andrade Filha - ledalessa@bahiana.edu.br Doutora em Psicologia. Psicóloga na Secretaria de Saúde do Estado da Bahia/Hospital Juliano Moreira. Professora na Escola Bahiana de Medicina e Saúde Pública e na Universidade Federal da Bahia. Salvador, Bahia, Brasil. ${ }^{2}$ Mestre em Psicologia do Desenvolvimento. Psicóloga no Núcleo de Oncologia da Bahia e responsável técnica na Clínica Hospsi. Professora na Escola Bahiana de Medicina e Saúde Pública, na Faculdade Ruy Barbosa. Salvador, Bahia, Brasil.

RESUMO I Os impasses referentes à transmissão do saber foram sinalizados por Freud na medida em que $\circ$ interesse na articulação entre a psicanálise e a pedagogia crescia, donde decorreu a sua afirmação sobre o impossível contido nos ofícios de educar, governar e psicanalisar. Este artigo apresenta uma experiência no ensino da psicologia com o uso do método PBL (Problem Based Learning). O ponto do qual se parte para uma análise é o dos deslocamentos ocorridos quando o professor passa à condição de tutor, e o eixo de abordagem das questões que aí se desdobram é a psicanálise - mais especificamente, os discursos conforme trabalhados por Lacan. Diante das dificuldades contemporâneas relacionadas à transmissão no âmbito do ensino - aqui, especificamente, o da psicologia -, as autoras pensam ser $\circ$ PBL uma alternativa interessante de trabalho em face dos métodos tradicionais, uma vez que ele, o PBL, mesmo sem assim o explicitar, permite instaurar $\circ$ discurso que visa $\circ$ desejo. Ademais, $\circ$ dispositivo próprio ao método - abertura e fechamento de problema, estabelecimento de objetivos de pesquisa a partir das discussões entre os alunos, participação do professor na condição de tutor produz incontestáveis deslocamentos na posição de saber, impactando o ato de ensinar e o trabalho de aprender. A experiência com $\circ \mathrm{PBL}$, se bem conduzida, convoca $\circ$ aluno à responsabilização pela sua produção, e o professor a declinar da usual conduta de ministrar a lição, de modo que fica valorizado o conhecimento como algo sempre a advir, e que se processa nas trocas coletivas.

Palavras-chave: Psicanálise. PBL. Psicologia

\begin{abstract}
This article presents an experience in the teaching of psychology with the use of PBL (Problem-Based Learning). The point of departure for the analysis is that of the displacements that occur when the teacher becomes tutor, and the theory that approaches the questions is psychoanalysis - more specifically, the discourses as worked by Lacan. The impasses concerning the transmission of knowledge were signaled by Freud insofar as the interest in the articulation between psychoanalysis and pedagogy grew up, from which came his assertion about the impossible contained in the offices of educating, governing and psychoanalysing. In face of the contemporary difficulties related to transmission in the field of teaching - specifically, psychology - the authors believe that PBL is an interesting alternative to work once considering traditional methods, since PBL allows us to establish the discourse that aims at the desire. In addition, the specificities of the method - opening and closing of problem, establishment of research objectives from the discussions among the students, participation of the teacher in the place of tutor... - produce incontestable displacements in the position of knowledge, impacting therefore the teaching and the learning. The experience with the PBL, if well conducted, convokes the student to be responsible for his production, and the teacher to decline from the usual procedure of teaching the lesson. This way. knowledge is something always about to emerge from the collective sharing.
\end{abstract}

Key words: Psychoanalysis. PBL. Psychology 


\section{Metodologias Ativas no Ensino da Psicologia: a Experiência com o PBL}

O curso de Psicologia da Escola Bahiana de Medicina e Saúde Pública tem contado, já há alguns anos, com experiências dos seus professores na utilização de métodos considerados ativos no ensino. Dentre as novas propostas metodológicas, está o PBL, o Problem Based Learning, ou Aprendizagem Baseada em Problemas.

A lide com estas inovações no ensino tem sido objeto de frequentes reflexões, uma vez que o método ativo de aprendizagem produz deslocamentos das posições usuais do professor e do aluno, convocando-os a ocupar lugares diversos daqueles do ensino tradicional e inventar novas modalidades de transmissão e aquisição do conhecimento.

No ensino da psicologia, os professores tanto têm de se haver com as demandas curriculares e alguns ideais que marcam os atos educativos, quanto estão às voltas com o constante desafio de refletir sobre - objeto privilegiado do seu campo de estudo, que é o sujeito em suas diferentes manifestações (sintomáticas, sociais, patológicas, comportamentais etc.). E em razão das situações-problema que são lançadas aos alunos semanalmente a fim de thes provocar o estudo e a pesquisa, as questões inerentes às manifestações subjetivas da contemporaneidade vêm ao primeiro plano.

São desafios que não param por aí. Como o curso de psicologia da Bahiana tem no Desenvolvimento do Ciclo de Vida (DCV) o eixo do seu ensino no formato PBL, os alunos vão encontrando, na medida mesma em que estudam os diferentes ciclos do desenvolvimento, razões para pensar aquilo sobre o que estudam, e aquilo que vivenciam, numa articulação intensa e potente que requer do professor - aqui, tutor - a plasticidade necessária para incentivar o ato da pesquisa e permitir, a um só tempo, a assimilação de saberes teóricos e a produção de um saber de si por parte do aluno.

A expectativa é que a aprendizagem assim produzida ocorra com autonomia, esta que, como relembra Rové (2009, p. 162), citando Thanasoulas (2002), envolve, entre outros aspectos, a apropriação, pelo aluno, do seu estilo de aprendizagem e do uso de suas estratégias, a disposição para cumprir as tarefas independentemente de estar sob avaliação, a adoção de um enfoque comunicativo no processo, a disposição para assumir riscos e cometer erros, a importância aos conceitos formais e sua assimilação. A experiência com o PBL, uma vez bem conduzida, convoca o aluno à responsabilização pela sua produção, ao tempo que convida o professor a declinar da usual conduta de ministrar a lição, de modo que fica valorizado o conhecimento como algo sempre a advir, e que se processa nas trocas coletivas.

Às voltas com estas reflexões, e instadas pelos desafios suscitados no trabalho com $\circ$ PBL, as autoras deste artigo, ambas de formação psicanalítica, surpreenderam-se por identificar aproximações entre $\circ$ dispositivo próprio ao método, e determinadas condições do trabalho analítico, configurando, assim, este escrito, que se propõe a identificar pontos de convergência entre a psicanálise e $\circ \mathrm{PBL}$, promovendo uma reflexão que se utiliza dos discursos de Lacan e trata da responsabilização e dos deslocamentos nas posições de saber.

\section{PBL e Psicanálise: Aprendendo com os Discursos}

Os impasses referentes à transmissão do saber foram sinalizados por Freud na medida em que - interesse na articulação entre a psicanálise e a pedagogia foi crescendo. No texto "Prefácio à Juventude Desorientada, de Aichhorn", Freud (1987 [1925]) cita a seguinte frase como um gracejo: “... aceitei $\circ$ bom mot que estabelece existirem três profissões impossíveis - educar, curar e governar" (p. 341). Como na psicanálise toda brincadeira traz marcas da verdade, toma-se aqui a tarefa de discutir os impasses inerentes a estes três ofícios, explorando tensões e aproximações.

Lacan, no Seminário 17 (1973/1985), afirma que cada realidade se funda e se define por um discurso, estabelecendo distintos laços sociais que visam mostrar as posições implicadas nos atos de governar, ensinar, analisar e desejar. O mal-estar da cultura, por sua vez, produz reordenamentos discursivos, repercutindo no ensino e gerando novos desafios, convocando constantemente a um reposicionamento dos sujeitos envolvidos. Inscreve- 
se, portanto, como uma pergunta a ensejar reflexões: diante das dificuldades contemporâneas relacionadas à transmissão do saber, não seria o PBL uma alternativa interessante em face dos métodos tradicionais, uma vez que, dentre outros aspectos, e mesmo sem assim o explicitar, permite instaurar o discurso que visa o desejo? Ademais, o dispositivo próprio ao método $\mathrm{PBL}$ - abertura e fechamento de problema, estabelecimento de objetivos de pesquisa a partir das discussões entre os alunos, participação do professor na condição de tutor, etc. - produz incontestáveis deslocamentos na posição de saber, impactando o ato de ensinar e o trabalho de aprender.

Outro ponto importante a ser destacado, donde mais uma vez a psicanálise vem em auxílio, é a importância da transferência de trabalho - e aqui, independente da metodologia de ensino ser ativa ou passiva. A contribuição da psicanálise com o campo da educação repousa significativamente no fato de estar aquela a relançar constantemente a interrogação sobre a tarefa educativa, "que supõe uma re-significação, a ser feita pelo professor, de sua atuação junto aos alunos" (Almeida, 2001).

Em moldes mais "tradicionais", o processo de ensino é comumente marcado por uma estrutura triangular, na qual os protagonistas são o professor e o aluno, sujeitos de desejo por definição, e o conhecimento é o objeto que aí circula. No formato PBL, o professor cede lugar para a figura do tutor. Trata-se de uma passagem que tem o caráter de um ato, e neste, o professor perde a sua investidura de ser aquele que porta um saber e irá transmiti-lo aos alunos, para responder de uma posição bastante diversa, na qual a sua principal função será a de permitir que o saber advenha de uma construção coletiva, iniciada pelas hipóteses dos alunos sobre tal ou qual problema disparador das discussões. $O$ professor, em outras palavras, é convocado, pelo dispositivo mesmo instaurado pelo método, a abrir mão de seu (suposto) poder fálico em função de possibilitar que novas significações e construções de saber sejam produzidas pelos alunos, que se fazem ativos no seu percurso de aprendizagem.
Esta mudança de posição do professor, favorecida pela necessária mudança de posição do aluno, evoca claramente $\circ$ reconhecimento do valor simbólico dos lugares no campo da aprendizagem. O tutor, afastado da condição de especialista, precisa suportar a perda implicada com um certo declínio do lugar de mestria; ele, contudo, não deixa de ocupar uma função de Outro supostosaber, pois é capaz de reconhecer e autenticar o movimento de conhecer do aluno. Trata-se, portanto, de uma posição ética, sobre a qual aqui se sugere que venha a ser pensada, por aproximação, com o discurso do analista (que será apresentado mais adiante).

O termo discurso, conforme a proposição de Lacan, acaba por adquirir uma acepção um tanto específica, e mesmo diversa daquela que ele próprio usara inicialmente, quando ele foi pensado no campo do simbólico, mais relacionado à fala, ao enunciado, ao dito. Com a criação do objeto a dáse uma passagem à ideia de criação dos discursos como laços sociais, vindo a afirmar Lacan (1992 [1969-1970]) que ele, o discurso, é sem palavras (na intenção mesma de que estas possam se alojar nele). Com isto, ele pretende apresentar certas estruturas lógicas, nas quais se encontram quatro lugares, ocupados pelos termos S1, S2, \$ e a, que se movimentam em rotações de quarto de giro. Temos, assim (Lacan, 1985 [1972-1973], p. 27):

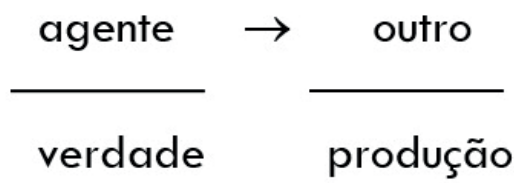

Para Lacan (1992 [1969-1970]), os discursos referem a maneira como cada sujeito se relaciona com o Outro, ou seja, com o código da linguagem. Quer dizer, indica como cada sujeito (\$) lida com a sua singularidade (S1) e se posiciona frente ao saber do Outro (S2), implicando numa forma particular de suportar o real, objeto $a^{a}$, e, com isto, estabelecer relacionamentos que visam governar, ensinar, analisar ou fazer desejar. Tem-se, assim, quatro discursos: 0 do Mestre, o do Universitário, o da Histérica e o do Analistab.

'O objeto a representa também a marca, o furo que existe na estrutura da linguagem, constituindo a possibilidade de existência do desejo.

bLacan apresentou um quinto discurso, o do capitalista, que surge da transformação do discurso do mestre por uma inversão dos termos do lado esquerdo, indicando que o sujeito não se dirige ao Outro, mas aos objetos, prescindindo do laço social. Lacan pouco trabalha este discurso, mencionando-o no Seminário 17 (1992 [1969-1970]), mas só o formalizando em uma conferência em Milão, em maio de 1972. 
Encontramos no Discurso do Mestre um meio privilegiado para expressar um dado modo de funcionamento da relação professor-aluno, conforme tradicionalmente ela costuma se apresentar:

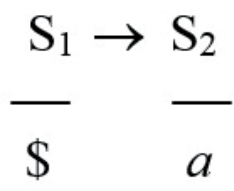

Neste discurso, a posição predominante (canto superior à esquerda) é ocupada por $\mathrm{S1}$, o significante mestre, ao qual se deve obediência. $O$ mestre se dirige ao escravo - S2 - que, ao trabalhar com afinco, produz o objeto que vai gerar a maisvalia, o excedente de gozo.

O que esta estrutura nos pode comunicar sobre a relação de ensino? Vejamos que há uma dimensão imperativa que queda do lado do mestre, inerente à sua condição, ficando o aluno na posição do S2, submetido ao caráter sugestivo emanado daquilo que $\circ$ mestre professa. Uma vez que $\circ$ professor se recuse a abrir mão do seu suposto poder fálico, e faça uso da relação transferencial imaginária para ser amado, sustentado que seja por fantasias de onipotência, ele pode deixar ao aluno o lugar do assujeitamento, da submissão ao desejo do mestre para que seja por este reconhecido e amado (Almeida, 2001, p. 2). É o que vemos nas relações estabelecidas sob hierarquias rígidas, nas quais se sobressai a figura do mestre explicador, suposto detentor de saberes totalizantes, mestre que encontra no aluno assujeitado, que busca ser reconhecido e amado, o seu contraponto.

O ensino tradicional também pode ser bem expresso pelo Discurso do Universitário:

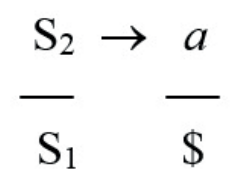

O Discurso do Universitário tem como agente o saber (S2), enquanto conhecimento organizado e acumulado, que se sustenta a partir do significante mestre (S1), ou seja, nos índices de confiabilidade de seus autores. Este conhecimento organizado se dirige ao outro tomando-o por um objeto (a) que pode ser apreendido pelo saber que se produz na universidade. $O$ S2 se coloca no lugar que foi inicialmente ocupado pelo mestre, lugar onde surgiu - saber. É uma modalidade de discurso que pode se dar à legitimação do Discurso do Mestre, através de racionalizações.

Discurso da Histérica assim se apresenta:

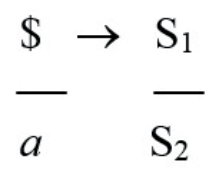

No lugar do agente está o sujeito dividido, que se endereça ao $\mathrm{S} 1$ dele esperando os significantes que produzirão um saber; é um sujeito que, cindido pelo sintoma, move-se pelo desejo de saber.

A histérica, de quem tanto Freud aprendeu, mostra a divisão subjetiva, a cisão entre consciente e inconsciente. Estar, neste discurso, na posição do \$, implica em um movimento de instigação do mestre para que ele gere um saber sobre o sintoma (mesmo que seja para, depois, invalidar as suas teorias). (Andrade Filha, 2013, p. 51).

Neste discurso, há uma produção de saber, portanto, sendo que o objeto $a$, objeto que causa $\circ$ desejo, se encontra no lugar da verdade, e está recalcado. Esta estrutura nos ajuda a pensar na posição do aluno que, ciente da sua divisão, se interessa pelo saber, esperando que algo possa vir do mestre lugar que pode ser representado pela ciência, por exemplo, enquanto suposto saber.

O quarto discurso a ser apresentado é o do Analista. Ele se configura pelo aresso do Discurso do Mestre:

$$
\frac{a}{\mathrm{~S}_{2}} \rightarrow \frac{\$}{\mathrm{~S}_{1}}
$$

O Discurso do Analista é o discurso no qual o agente se dirige ao outro enquanto sujeito. $O$ analista, ao não responder à demanda do paciente, situase como objeto-causa-de-desejo, instaurando o Sujeito-suposto-Saber (SsS). O S2 aparece no lugar da verdade, mas representando não um saber que se pretende totalizante, e sim um saber inconsciente. Se o analista, do lugar de objeto, se dirige ao sujeito para que este enuncie os significantes dos quais é efeito, no PBL é o tutor quem, declinando do lugar 
de mestria, permite que 0 aluno se responsabilize pela sua produção. O conhecimento, aí, é sempre algo a advir, e surge como uma construção a partir de trocas coletivas.

\section{Os Deslocamentos na Posição de Saber: Ética e Desejo}

No Seminário de 1954, "O eu na teoria de Freud..." (1985 [1954-55]) ', Lacan comenta que a posição do professor perante o saber é sempre de suficiência, quando nada, em aparência:

[...] nunca se viu um professor estar em falta por ignorância. Sempre se sabe o suficiente para preencher os minutos durante os quais a gente se expõe na posição daquele que sabe. Nunca se viu ninguém ficar desprovido do que dizer a partir do momento que ele toma a posição de ser aquele que ensina. (p. 260).

No âmbito dos desafios que a contemporaneidade nos impõe - conquanto saibamos que as fantasias de onipotência e de domínio permaneçam marcando - narcisismo do homem moderno, tributário do desfrute dos incessantes objetos que o capitalismo põe ao seu dispor -, não parece que ainda seja possível permanecer inteiramente nos registros tradicionais do ensino pautado nas relações duras e hierarquizadas, limitadas às paredes das salas de aula.

Educar, este impossível ofício, tão carregado de impasses e desafios, segue sendo um revelador do mal-estar da cultura. Hoje tanto se fala dos embaraços do professor para lidar com a situação do aluno que, mergulhado em um cenário marcado pelo excesso (de informações, de consumo, de tecnologias, de gadgets...), confunde saber com informação, expondo a dificuldade de se haver com - impacto das novas tecnologias na sua promessa de 'tudo estar disponível'. Artigos e teses e análises dizem da falência da transmissão na relação professor-aluno, reconhecendo que a globalização e o mercado de saber impuseram à cultura novas vestimentas. A queda de hierarquias que outrora se punham a organizar algumas bases do tecido social, ao lado do declínio da função paterna, da vida sob uma economia que antes era organizada pelo recalque e hoje o é pelo gozo (Melman, 2003, p. 16), parece exigir intensos deslocamentos daquele que se dispõe à tarefa de educar.

Mostra-se, neste artigo, como os discursos da histérica e do analista permitem que se enseje renovadas reflexões sobre o PBL. $O$ discurso da histérica é - discurso do fazer desejar, algo facilitado pelo dispositivo do método, que também abre para o desejar. No que tange ao do analista, tem-se que, no PBL, também por conta do dispositivo que ele instaura, o professor é convocado a deixar de responder do lugar de mestre para se conduzir ao seu avesso, como o faz o analista. No momento em que o tutor se cala, ele se faz de agalma: enquanto agente, o seu lugar é $\circ$ de permitir que $\circ$ desejo aceda. E o aluno, aqui, encontra como possibilidade produzir um saber que pode ser ouvido, partilhado, valorizado, e mesmo autenticado na sua condição de resultado de uma criação, de uma palavra própria.

Mas se o PBL, como um entre outros métodos ativos, favorece novas invenções e condutas, é preciso dizer que a estrutura metodológica não garante, por si mesma, a queda de hierarquias rígidas, descomprometidas com o propósito transformador que $\circ$ ato de educar pressupõe. Um excessivo controle na escolha dos temas e problemas, a pouca abertura que o tutor dê ao saber engendrado nas discussões, as expectativas de uma mera reprodução de conhecimentos presente nas avaliações, entre outros aspectos, são elementos que nos alertam sobre a necessidade de declinar dos maniqueísmos.

O professor, uma vez tendo se dado conta da falta que the é inerente, precisa operar com o seu próprio desejo de saber, fazendo deste a causa de desejo para $\circ$ aluno. Navega-se sobre um dilema ético afinal, quando se trata de ensinar, psicanalisar e governar, o final é sempre incerto.

\section{CONFLITOS DE INTERESSES}

Nenhum conflito financeiro, legal ou político envolvendo terceiros (governo, empresas e fundações privadas, etc.) foi declarado para nenhum aspecto do trabalho submetido (incluindo mas não limitandose a subvenções e financiamentos, conselho consultivo, desenho de estudo, preparação de manuscrito, análise estatística, etc). 


\section{REFERÊNCIAS}

Almeida, S.F.C. de. (2001). Psicanálise e educação: revendo algumas observações e hipóteses a respeito de uma (im)possível conexão. In: Colóquio do LEPSI IP/ FE-USP, 3., São Paulo. Recuperado de http:// www.proceedings.scielo.br/scielo.php?script=sci_ MSC000000003200100030001 1 \&lng =en\&nrm $=a b n$

Andrade Filha, L. L. (2013). O trabalho psicanalítico no ambulatório do Hospital Juliano Moreira: reflexões sobre a clínica do sujeito. Tese de doutorado, Instituto de Psicologia, Universidade Federal da Bahia, Salvador, Bahia, Brasil

Freud, S. (1925/1987). Prefácio à Juventude Desorientada, de Aichhorn. In: Edição Standard Brasileira das Obras Psicológicas Completas de Sigmund Freud, vol. XIX. Rio de Janeiro: Imago

Lacan, J. (1954-1955/1985). O Seminário, livro 2: o eu na teoria de Freud e na técnica da psicanálise. (Versão Marie Christine Laznik Penot com a colaboração de Antonio Luiz Quinet de Andrade). Rio de Janeiro: Jorge Zahar Ed

Lacan, J. (1969-1970/1992). O Seminário, livro 17: o avesso da psicanálise. (Versão Ari Roitman). Rio de Janeiro: Jorge Zahar Ed

Lacan, J. (1972-1973/1985). O Seminário, livro 20: mais, ainda. (Versão M. D. Magno). Rio de Janeiro: Jorge Zahar

Melman, C. (2003). O homem sem gravidade: gozar a qualquer preço. (Sandra R. Felgueiras, Trad.). Rio de Janeiro: Companhia de Freud

Rové, J. (2009). Aprender com autonomia no ensino superior. In: Sartre, G.; Araújo, U.F. (orgs.) Aprendizagem Baseada em Problemas. São Paulo: Summus 